\title{
Structural Investigation of Cell Wall Mannan Antigen Obtained from Pathogenic Yeast Candida zeylanoides
}

\author{
Hidemitsu Kobayashi ${ }^{1}$, Susumu Kawakami ${ }^{1}$, Yukiko Ogawa ${ }^{1}$, \\ Nobuyuki Shibata ${ }^{2}$, Shigeo Suzuki ${ }^{3}$ \\ ${ }^{1}$ Laboratory of Microbiology, Faculty of Pharmaceutical Science, Nagasaki International University, Sasebo, Nagasaki, Japan \\ ${ }^{2}$ Department of Infection and Host Defense, Tohoku Pharmaceutical University, Sendai, Miyagi, Japan \\ ${ }^{3}$ Sendai Research Institute for Mycology, Sendai, Miyagi, Japan \\ Email: h-kobaya@niu.ac.jp
}

Received April 4, 2013; revised May 5, 2013; accepted May 14, 2013

Copyright (C) 2013 Hidemitsu Kobayashi et al. This is an open access article distributed under the Creative Commons Attribution License, which permits unrestricted use, distribution, and reproduction in any medium, provided the original work is properly cited.

\begin{abstract}
Antigenicity of pathogenic yeast Candida zeylanoides NBRC 10326 was found to have similar to that of Candida guilliermondii, but it was slightly different, i.e. NBRC 10326 strain cells react strongly with the factor antibodies 1,4 , and 9 , and react relatively weakly with factor antibody 5 . We have investigated the structural characteristic of cell wall mannan of this strain using a non-degradable method, nuclear magnetic resonance analysis. The results obtained from NMR analysis, the two-dimensional homonuclear Hartmann-Hahn, indicated that C. zeylanoides mannan contains $\alpha-1$, 3-linked and $\beta$-1,2-linked oligomannosyl side chains corresponding to $C$. guilliermondii specific antigenic factor 9. In addition, it was found that the mannan contains $\beta$-1,2-linked oligomannosyl side chains attached to phosphate groups corresponding to anitigenic factor 5 , which were not found in $C$. guilliermondii mannan.
\end{abstract}

Keywords: Candida zeylanoides; Candida guilliermondii; Cell Wall Mannan; Antigenic Factor; Nuclear Magnetic Resonance

\section{Introduction}

Ten rabbit antibodies to antigenic factors of genus Candida (abbreviated as FAbs) was developed to identify clinical isolates from the patients with candidiasis by Fukazawa et al. [1] and Tsuchiya et al. [2,3]. These FAbs recognize the antigenic determinants in cell wall mannan of genus Candida [4]. We reported the chemical structure of cell wall mannans of several Candida species, including C. albicans [5], C. tropicalis [6] and C. guilliermondii [7]. Moreover, we revealed that the determinants of antigenic factors 5,6 , and 9 correspond to the oligomannosyl side chains containing $\beta$-1,2-linked mannose residue [7-9]. On the other hand, the determinants of Candida factors 1, 4, 13b, and 34 are $\alpha$-linked oligomannosyl side chains [10-12].

Candida zeylanoides is one of the opportunistic pathogen for candidiasis $[13,14]$, and its cell wall mannan would be responsible for most of antigenic activity of the cell surface. The chemical structure of the antigenic mannan of this pathogen has not yet been determined. In the present study, we analyzed the purified mannan of $C$. zeylanoides NBRC 10326 strain by a non-degradable me- thod, two-dimensional nuclear magnetic resonance.

\section{Materials and Methods}

\subsection{Strains and Culture}

C. zeylanoides NBRC 10326 strain (abbreviated as Zstrain), C. guilliermondii NBRC 10279 strain (abbreviated as G-strain), and C. albicans NBRC 1060 strain (serotype A) were obtained from the Biological Resource Center (NBRC), National Institute of Technology and Evaluation (NITE), Japan. C. albicans NIH B-792 strain (serotype B) was gift from Dr. T. Shinoda, Meiji College of Pharmacy, Tokyo, Japan. The cells of these strains were cultivated in the yeast extract-Sabouraud's liquid medium $[0.5 \%(\mathrm{w} / \mathrm{v})$ yeast extract, $1 \%(\mathrm{w} / \mathrm{v})$ peptone, and $2 \%(\mathrm{w} / \mathrm{v})$ glucose $]$ at $27^{\circ} \mathrm{C}$ for $72 \mathrm{hrs}$ on a reciprocal shaker.

\subsection{Slide Agglutination Reaction of the Cells of Z-Strain Cells with Factor Antibodies (FAbs)}

Slide agglutination reaction was carried out as previously 
described [15]. Factor antibodies of the genus Candida (abbreviated as FAbs) 1, 4, 5, 6, 8, 9, 11, 13, 13b, and 34 were prepared by Fukazawa et al. [1]. The agglutinations of $C$. albicans and C. guilliermondii cells are shown for comparative purposes.

\subsection{Preparation of Mannan from Z-Strain}

Mannans were extracted with hot water and precipitated by short-term treatment with Fehling solution [16]. The mannan obtained from the Z-strain was designated Fr. Z. The yield of Fr. $Z$ was $10.5 \%$ of the dry cell weight.

\subsection{Nuclear Magnetic Resonance (NMR) Analysis of Fr. Z}

${ }^{1} \mathrm{H}$-nuclear magnetic resonance ( $\left.{ }^{1} \mathrm{H}-\mathrm{NMR}\right)$ and two-dimensional homonuclear Hartmann-Hahn (2D-HOHAHA) spectrograph were recorded using $\mathrm{D}_{2} \mathrm{O}$ at $45^{\circ} \mathrm{C}$ with acetone as the internal standard (2.217 ppm) on a Jeol JNMGSX 400 spectrometer. The percentage of the different kinds of oligomannosyl side chains in Fr. Z was calculated based on the peak dimensions of the corresponding H-1 signals in the ${ }^{1} \mathrm{H}-\mathrm{NMR}$ spectrum [17].

\subsection{Other Methods}

Total carbohydrate was determined by the phenol- $\mathrm{H}_{2} \mathrm{SO}_{4}$ method [18] using mannose as a standard. Total protein was determined by the Folin method of Lowry et al. [19] using bovine serum albumin as a standard. Total phosphate was determined using the Ames-Dubin method [20] using $\mathrm{KH}_{2} \mathrm{PO}_{4}$ as the standard.

\section{Results and Discussion}

The results of the slide-agglutination assays of Z-strain cells with factor antibodies of the genus Candida are shown in Table 1. FAbs 1, 4, 5, and 9 are significantly positive to the Z-strain cells. Fab 1 is the antibody against common antigen of genus Candida that reacts with most of Candida species. The recognition of FAbs 4 and 5 suggests that Z-strain mannan contains the common antigen of two Candida species, C. albicans and C. tropicalis.
The recognition of FAbs 9 suggests that the determinant of specific antigen of $C$. guilliermondii is contained in Z-strain mannan. The lack of response to FAbs 6 and 13b suggests that the mannan does not contain the side chains corresponding to specific antigen of $C$. albicans serotype $\mathrm{A}$ and $\mathrm{B}$. Therefore, the chemical structure of Z-strain mannan may be a crossbreed with that of the mannans of C. guilliermondii [7], C. albicans [5], and/or C. tropicalis [6].

Component analysis indicated that Fr. Z contained $94.4 \%$ total carbohydrate, $2.5 \%$ total protein, and $1.1 \%$ total phosphate. The phosphate group that was not previously observed in the mannan of $C$. guilliermondii [7] was detected in Fr. Z. This finding agreed with the positive reactivity of $Z$-strain cells against FAb 5 in the slideagglutination (Table 1).

The chemical structure of Fr. $\mathrm{Z}$ was analyzed by means of 2D-HOHAHA (Figure 1). All H-1-H-2 crosspeaks were assigned according to published data [21-25] as shown in Table 2. The quartet signal corresponding peak 1 at $5.4-5.7 \mathrm{ppm}$ indicates the presence of the phosphorylated oligomannosyl side chain and $\beta$-1,2-linked oligomannosyl unit. This result is intended to support the two facts that Fr. Z contains phosphate group and Zstrain cells react with Fab 5 (Table 1). The high intensity of H-1-H-2 cross-peak 6 indicates the presence of branched side chains containing $\alpha-1,2-, \alpha-1,3-$ and $\alpha-1,6-$ linked mannose residues. In addition, two $\mathrm{H}-1-\mathrm{H}-2$ crosspeaks 2 and 7 correspond to the internal and non-reducing terminal $\alpha$-1,3-linked mannose residues, respectively. The high intensity of H-1-H-2, H-1-H-4 and H-2-H-4 cross-peaks 11,16 and 17 of the non-reducing terminal $\alpha-1,6$-linked mannose also indicated the presence of a 3,6-branched side chain. Both cross-peaks of two kinds of non-reducing terminal $\alpha-1,3$-linked mannose residues in a linear side chain and in a branched side chain appear in a similar range (cross-peak 7: H-1, 5.132 ppm; H-2, $4.064 \mathrm{ppm}$ ). The total peak dimension of two H1-signals at $5.363 \mathrm{ppm}$ and at $5.132 \mathrm{ppm}$ was not in agreement with that of the H-1 signal at $4.924 \mathrm{ppm}$ corresponding to the non-reducing terminal $\alpha-1,6$-linked mannose. These results indicate that Fr. $\mathrm{Z}$ contains the small amount of

Table 1. Slide agglutination assay for whole cells of $C$. zeylanoides, C. guilliermondii, and C. albicans with anti-Candida factor antibodies, FAbs.

\begin{tabular}{|c|c|c|c|c|c|c|c|c|c|}
\hline \multirow{2}{*}{ Strain } & \multicolumn{9}{|c|}{ Agglutination $^{\mathrm{a}}$ with FAb } \\
\hline & 1 & 4 & 5 & 6 & 8 & 9 & 11 & $13 b$ & 34 \\
\hline C. zeylanoides NBRC 10326 & ++ & ++ & + & - & - & ++ & - & - & - \\
\hline C. guilliermondii NBRC $10279^{\mathrm{b}}$ & ++ & + & - & - & - & ++ & - & - & - \\
\hline C. albicans NBRC 1060 (serotype A) & ++ & ++ & + & + & - & - & - & - & - \\
\hline C. albicans NIH B-792 (serotype B) & ++ & ++ & + & - & - & - & - & + & - \\
\hline
\end{tabular}

${ }^{\mathrm{a}}$ Agglutination was scored from high $(++)$ to low $(+)$ and no agglutination $(-) ;{ }^{\mathrm{b}}$ The agglutinations of $C$. albicans and $C$. guilliermondii cells are shown for comparative purposes. 

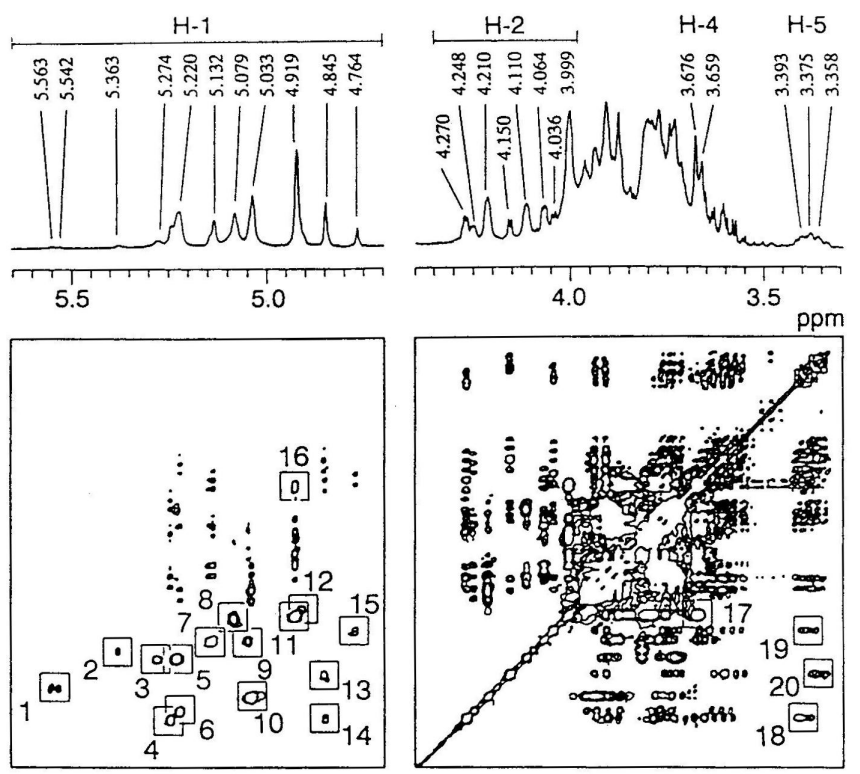

Figure 1. 2D-HOHAHA spectrum of Fr. Z. This was conducted at $45^{\circ} \mathrm{C}$ using acetone $(2.217 \mathrm{ppm})$ as an internal standard.

Table 2. Assignment of chemical shifts of cross-peaks in 2D-HOHAHA map of Fr. Z.

\begin{tabular}{|c|c|c|c|}
\hline \multirow[t]{2}{*}{ Cross-peak } & \multicolumn{2}{|c|}{ Chemical shift (ppm) ${ }^{\mathrm{a}}$} & \multirow[t]{2}{*}{ Sugar residue $^{\mathrm{b}}$} \\
\hline & $\mathrm{H}-1$ & $\mathrm{H}-2$ & \\
\hline \multirow[t]{2}{*}{1} & 5.563 & - & $\beta 1-2 \mathrm{M} \alpha 1-\mathrm{H}_{2} \mathrm{PO}_{3}$ \\
\hline & 5.542 & - & \\
\hline 2 & 5.363 & 4.089 & $\alpha 1-2 \mathrm{M} \alpha 1-3$ \\
\hline 3 & 5.274 & 4.110 & $\alpha-1-2 \mathrm{M} \alpha 1-2$ \\
\hline 4 & 5.248 & 4.27 & $\beta 1-2 \mathrm{M} \alpha 1-3$ \\
\hline \multirow[t]{3}{*}{5} & 5.220 & 4.105 & $(\alpha 1-3 \mathrm{M}) \alpha 1-2 \mathrm{M} \alpha 1-2$ \\
\hline & & & $\uparrow 6$ \\
\hline & & & $\alpha 1$ \\
\hline 6 & 5.220 & 4.248 & $(\beta 1-2 \mathrm{M}) \beta 1-2 \mathrm{M} \alpha 1-3$ \\
\hline 7 & 5.132 & 4.064 & $\mathrm{M} \alpha 1-3$ \\
\hline \multirow[t]{3}{*}{8} & 5.079 & 4.01 & $\alpha 1-6 \mathrm{M} \alpha 1-6$ \\
\hline & & & $\uparrow 2$ \\
\hline & & & $\alpha 1$ \\
\hline 9 & 5.049 & 4.064 & $\mathrm{M} \alpha 1-2$ \\
\hline 10 & 5.037 & 4.21 & $\alpha 1-3 \mathrm{M} \alpha 1-2$ \\
\hline 11 & 4.919 & 3.999 & $\mathrm{M} \alpha 1-6$ \\
\hline 12 & 4.906 & 3.995 & $\alpha 1-6 \mathrm{M} \alpha 1-6$ \\
\hline 13 & 4.848 & 4.15 & $\mathrm{M} / 1-2(\mathrm{M} / 1-2 \mathrm{M} \alpha 1-3)$ \\
\hline 14 & 4.842 & 4.27 & $\beta 1-2 \mathrm{M} \beta 1-2(\mathrm{M} \alpha 1-3)$ \\
\hline 15 & 4.767 & 4.036 & $\mathrm{M} \beta 1-2(\mathrm{M} \alpha 1-3)$ \\
\hline \multirow[t]{2}{*}{16} & 4.919 & 3.668 & $\mathrm{M} \alpha 1-6$ \\
\hline & (H-1) & $(\mathrm{H}-4)$ & \\
\hline \multirow[t]{2}{*}{17} & 3.999 & 3.668 & $\mathrm{M} \alpha 1-6$ \\
\hline & $(\mathrm{H}-2)$ & $(\mathrm{H}-4)$ & \\
\hline \multirow[t]{2}{*}{18} & 4.842 & 3.393 & $\beta 1-2 \mathrm{M} \beta 1-2(\mathrm{M} \alpha 1-3)$ \\
\hline & $(\mathrm{H}-2)$ & $(\mathrm{H}-5)$ & \\
\hline \multirow[t]{2}{*}{19} & 4.049 & 3.387 & $\mathrm{M} \beta 1-2(\mathrm{M} \alpha 1-3)$ \\
\hline & (H-2) & $(\mathrm{H}-5)$ & \\
\hline
\end{tabular}

${ }^{\mathrm{a}}$ Measured using acetone $(2.217 \mathrm{ppm})$ as a standard; ${ }^{\mathrm{b}} \mathrm{M}$ denotes a mannose residue. 
$\alpha-1,3$-linkage-containing linear side chains. The appearance of H-1-H-2 cross-peaks 3 and 12 and $\mathrm{H}-2-\mathrm{H}-5$ cross-peak 15 indicates the presence of $\beta-1,2-$ and $\alpha-1,3-$ linked oligomannosyl residues. Unfortunately, it is difficult to distinguish several overlapping signals, $\mathrm{H}-1$ and $\mathrm{H}-2$ ranges of $5.25-5.30 \mathrm{ppm}$ and $4.10-4.12 \mathrm{ppm}$, corresponding to the inner $\alpha$-1,2-linked mannose in the side chains.

As a result of the present study, the chemical structure of Fr. $\mathrm{Z}$ and the recognition sites of FAbs have been shown in Figure 2. The $\alpha$-1,2-linked oligomannosyl side chains and the 3,6-branched side chains corresponding to the determinants of antigenic factors 1 and 4 are presented in Fr. Z. Furthermore, Fr. Z possess the determinants of antigenic factors 5 and 9 , which were previously observed in the mannans of C. guilliermondii [7] and the both serotypes of $C$. albicans [8]. However, Fr. F does not possess the determinant of antigenic factors 6 , which was previously observed in the mannans of $C$. albicans serotype A [16,23]. Even though the cells of Z-strain do

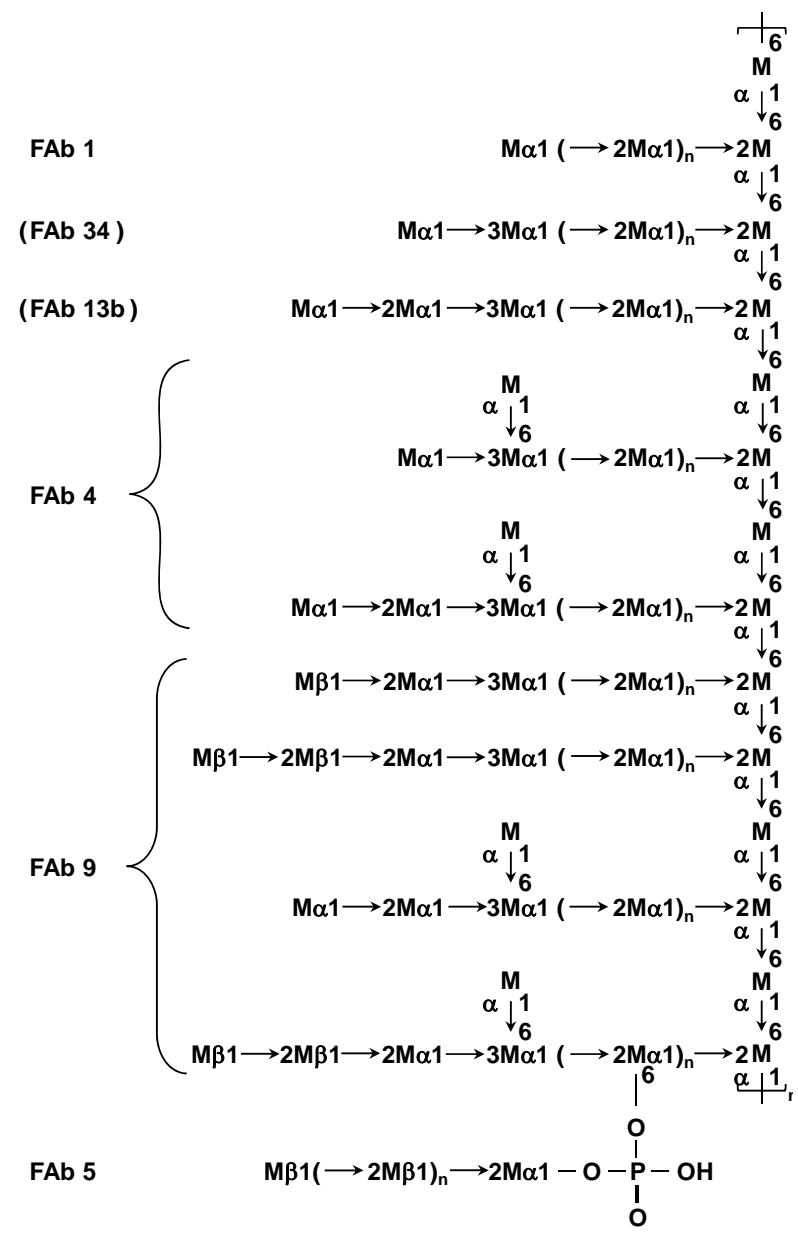

Figure 2. Structure of Fr. $\mathrm{Z}$ and the side chains corresponding to antigenic factors $1,4,5$, and $9 . M$ denotes a mannose residue. Side chain sequence is not specified. The repeat count "n" is not determined. not react with factor antibodies $13 \mathrm{~b}$ and 34 (Table 1), the side chains corresponding to antigenic factors $13 \mathrm{~b}$ and 34 were detected in Fr. Z by NMR analysis (Figure 1 and Table 2). This phenomenon may be due to the steric hindrance in the mannan molecule, i.e., it is estimated that a relatively short $\alpha$-linked oligomannosyl side chains are shielded by the long $\beta$-1,2-linkage-containing oligomannnosyl side chains on the Z-strain cell surface.

\section{REFERENCES}

[1] Y. Fukazawa, T. Shinoda and T. Tsuchiya, "Response and Specificity of Antibodies for Candida albicans," Journal of Bacteriology, Vol. 95, No. 3, 1968, pp. 754-763.

[2] T. Tsuchiya, Y. Fukazawa and S. Kawakita, "A Method for the Rapid Identification of the Genus Candida," Mycopathologia, Vol. 10, No. 3, 1959, pp. 191-206.

[3] T. Tsuchiya, Y. Fukazawa, M. Taguchi, T. Nakase and T. Shinoda, "Serologic Aspects on Yeast Classification," Mycopathologia, Vol. 53, No. 1-4, 1974, pp. 77-92.

[4] T. Shinoda, L. Kaufman and A. A. Padhye, "Comparative Evaluation of the Iatron Serological Candida Check Kit and the API 20C Kit for Identification of Medically Important Candida Species," Journal of Clinical Microbiology, Vol. 13, No. 3, 1981, pp. 513-518.

[5] N. Shibata, H. Kobayashi and S. Suzuki, "Immunochemistry of Pathogenic Yeast Candida Species, Focusing on Mannan," Proceeding of the Japanese Academy Series B: Physical and Biological Sciences, Vol. 88, No. 6, 2012, pp. 250-265. doi:10.2183/pjab.88.250

[6] H. Kobayashi, H. Oyamada, K. Matsuda, N. Shibata and S. Suzuki, "Distribution of Antigenic Oligomannosyl Side Chains in the Cell Wall Mannans of Several Strains of Candida tropicalis," Archives of Microbiology, Vol. 180, No. 1, 2003, pp. 76-80. doi:10.1007/s00203-003-0550-7

[7] N. Shibata, R. Akagi, T. Hosoya, K. Kawahara, A. Suzuki, K. Ikuta, H. Kobayashi, K. Hisamichi, Y. Okawa and S. Suzuki, "Existence of Novel Branched Side Chains Containing $\beta-1,2$ and $\alpha-1,6$ Linkages Corresponding to Antigenic Factor 9 in the Mannan of Candida guilliermondii," Journal of Biological Chemistry, Vol. 271, No. 16, 1996, pp. 9259-9266. doi:10.1074/jbc.271.16.9259

[8] N. Shibata, M. Arai, E. Haga, T. Kikuchi, M. Najima, T. Satoh, H. Kobayashi and S. Suzuki, "Structural Identification of an Epitope of Antigenic Factor 5 in Mannans of Candida albicans NIH B-792 (Serotype B) and C. albicans J-1012 (Serotype A) as $\beta$-1,2-Linked Oligomannosyl Residues," Infection and Immunity, Vol. 60, No. 10, 1992, pp. 4100-4110.

[9] H. Kobayashi, N. Shibata and S. Suzuki, "Evidence for Oligomannosyl Residues Containing both $\beta-1,2$ and $\alpha-1,2$ Linkages as a Serotype A-Specific Epitope(s) in Mannans of Candida albicans," Infection and Immunity, Vol. 60, No. 5, 1992, pp. 2106-2109.

[10] M. Funayama, A. Nishikawa, T. Shinoda and Y. Fukazawa, "Immunochemical Determinant of Candida parapsilosis," Carbohydrate Research, Vol. 117, 1983, pp. 229239. doi:10.1016/0008-6215(83)88089-6 
[11] N. Shibata, K. Ikuta, T. Imai, Y. Satoh, R. Satoh, A. Suzuki, C. Kojima, H. Kobayashi, K. Hisamichi and S. Suzuki, "Existence of Branched Side Chains in the Cell Wall Mannan of Pathogenic Yeast, Candida albicans. Structure-Antigenicity Relationship between the Cell Wall Mannans of Candida albicans and Candida parapsilosis," Journal of Biological Chemistry, Vol. 270, No. 3, 1995, pp. 1113-1122. doi:10.1074/jbc.270.3.1113

[12] H. Kobayashi, H. Oyamada, A. Suzuki, N. Shibata, S. Suzuki and Y. Okawa, "Identification of the Antigenic Determinants of Factors 8, 9, and 34 of Genus Candida," FEBS Letters, Vol. 395, No. 2-3, 1996, pp. 109-112. doi:10.1016/0014-5793(96)01013-7

[13] W. J. Crozier, "Two Cases of Onychomycosis Due to $\mathrm{Ca}$ dida zeylanoides," Australasian Journal of Dermatology, Vol. 34, No. 1, 1993, pp. 23-25. doi:10.1111/j.1440-0960.1993.tb00842.x

[14] K. N. Prasad, J. Agarwal, A. K. Dixit, D. P. Tiwari, T. N. Dhole and A. Ayyagari, "Role of Yeasts as Nosocomial Pathogens \& Their Susceptibility to Fluconazole \& Amphotericin B," Indian Journal of Medical Research, Vol. 110, 1999, pp. 11-17.

[15] Y. Miyakawa, K. Kagaya and Y. Fukazawa, "Production and Characterization of Agglutinating Monoclonal Antibodies against Predominant Antigenic Factors for Candida albicans," Journal of Clinical Microbiology, Vol. 23, No. 5, 1986, pp. 881-886.

[16] H. Kobayashi, N. Shibata, H. Mitobe, Y. Ohkubo and S. Suzuki, "Structural Study of Phosphomannan of YeastForm Cells of Candida albicans J-1012 Strain with Special Reference to Application of Mild Acetolysis," Archives of Biochemistry and Biophysics, Vol. 272, No. 2, 1989, pp. 364-375. doi:10.1016/0003-9861(89)90230-0

[17] H. Kobayashi, J. Suzuki, S. Tanaka, Y. Kiuchi, H. Oyamada, N. Iwadate, H. Suzuki, N. Shibata, S. Suzuki and Y. Okawa, "Structure of a Cell Wall Mannan from the Pathogenic Yeast, Candida catenulata: Assignment of ${ }^{1} \mathrm{H}$ Nuclear Magnetic Resonance Chemical Shifts of the Inner $\alpha$-1,6-Linked Mannose Residues Substituted by a Side Chain," Archives of Biochemistry and Biophysics, Vol. 341, No. 1, 1997, pp. 70-74. doi:10.1006/abbi.1997.9939

[18] M. Dubois, K. A. Gilles, J. K. Hamilton, P. A. Rebers and
F. Smith, "Colorimetric Method for Determination of Sugars and Related Substances," Analytical Chemistry, Vol. 28, No. 3, 1956, pp. 350-356. doi:10.1021/ac60111a017

[19] O. H. Lowry, N. J. Rosebrough, A. L. Farr and R. J. Randall, "Protein Measurement with the Folin Phenol Reagent," Journal of Biological Chemistry, Vol. 193, No. 1, 1951, pp. 265-275.

[20] B. N. Ames and D. T. Dubin, "The Role of Polyamines in the Neutralization of Bacteriophage Deoxyribonucleic Acid,' Journal of Biological Chemistry, Vol. 235, No. 3, 1960, pp. 769-775.

[21] H. Kobayashi, N. Shibata, M. Watanabe, M. Komido, N. Hashimoto, K. Hisamichi and S. Suzuki, "Mild Acetolysis and NMR Studies of the D-Mannan of Saccharomyces cerevisiae X2180-1A Wild-Type Strain," Carbohydrate Research, Vol. 231, 1992, pp. 317-323. doi:10.1016/0008-6215(92)84028-Q

[22] H. Kobayashi, H. Oyamada, N. Iwadate, H. Szuki, H. Mitobe, K. Takahashi, N. Shibata, S. Suzuki and Y. Okawa, "Structural and Immunochemical Characterization of $\beta$-1,2-Linked Mannobiosyl Phosphate Residue in the Cell Wall Mannan of Candida glabrata," Archives of Microbiology, Vol. 169, No. 3, 1998, pp. 188-194. doi:10.1007/s002030050559

[23] N. Shibata, A. Suzuki, Y. H. Kobayashi and Y. Okawa, "Chemical Structure of the Cell-Wall Mannan of Candida albicans Serotype A and Its Difference in Yeast and Hyphal Forms," Biochemical Journal, Vol. 404, No. 3, 2007, pp. 365-372. doi:10.1042/BJ20070081

[24] H. Oyamada, Y. Ogawa, N. Shibata, Y. Okawa, S. Suzuki and H. Kobayashi, "Structural Analysis of Cell Wall Mannan of Candida sojae, a New Yeast Species Isolated from Defatted Soybean Flakes," Archives of Microbiology, Vol. 189, No. 5, 2008, pp. 483-890. doi:10.1007/s00203-007-0339-1

[25] N. Shibata and Y. Okawa, "Enzymatic Synthesis of New Oligosaccharides using Mannosyltransferases from Candida Species and their NMR Assignment," Biological \& Pharmaceutical Bulletin, Vol. 33, No. 5, 2010, pp. 895899. doi: $10.1248 / \mathrm{bpb} .33 .895$ 